\title{
REFLEXÕES EM TORNO DAS RELAÇÕES ENTRE DOCENTES E EDUCANDOS/AS NA EDUCAÇÃO DE PESSOAS JOVENS E ADULTAS: CAMINHOS QUE SE ENCONTRAM NA BUSCA PELA GARANTIA DE UM DIREITO
}

\author{
Trinidad Vaccarezza ${ }^{1}$ \\ Leôncio Soares ${ }^{2}$
}

\section{RESUMO}

Este artigo traz para a reflexão as relações que se constroem entre docentes e educandos/as da Educação de Pessoas Jovens e Adultas (EPJA) em escolas da Rede Municipal de Educação de Belo Horizonte (RME-BH). As análises apresentadas partem de uma pesquisa realizada com docentes de ampla trajetória de trabalho na modalidade, que variam entre 11 e 32 anos de experiência no campo. Com o objetivo de descrever e analisar essas relações, o artigo indaga sobre como os/as docentes participantes da pesquisa reconhecem as especificidades dos sujeitos que frequentam a EPJA na RME-BH e constroem, junto com eles/as e na interação com a comunidade, um conjunto de práticas cuja finalidade é a busca pela garantia do direito à educação de todas as pessoas que chegam na EPJA, destacando a dimensão ética e política do fazer educativo.

Palavras-chave: Docência na EPJA. Relações entre docentes e educandos/as da EPJA. Direito à EPJA.

\footnotetext{
${ }^{1}$ Mestre em Educação pela Universidade Federal de Minas Gerais. Licenciada em Ciências da Educação pela Universidad de Buenos Aires, Argentina. Integrante do Grupo de Pesquisa em Educação de Jovens e Adultos (GRUPEJA). ORCID: https://orcid.org/00000001-5183-9891. E-mail: trinidadvaccarezza@gmail.com

2 Doutor em Educação pela Universidade de São Paulo. Professor Titular do curso de Pedagogia e do Programa de Pós-graduação em Educação da Faculdade de Educação da Universidade Federal de Minas Gerais. ORCID: https://orcid.org/0000-0003-47502529. E-mail: leonciogsoares@gmail.com
} 


\section{REFLECTIONS ON THE RELATIONSHIP BETWEEN TEACHERS AND STUDENTS IN YAE: PATHS THAT MEET IN THE SEARCH FOR THE GUARANTEE OF A RIGHT}

\section{ABSTRACT}

This paper aims to reflect on the relationships built between teachers and students of Youth and Adult Education (YAE) in schools of the Rede Municipal de Educação de Belo Horizonte (RME-BH). The proposed analyses are based on research conducted with teachers who have extensive work trajectories in the modality, ranging from 11 to 32 years of experience. With the aim of describing and analyzing these relationships, the paper explores how the teachers participating in the research recognize the specificities of the individuals who attend YAE at RME-BH and build, together with them and in interaction with the community, a set of practices whose purpose is to ensure the right to education of all people who attend $Y A E$, highlighting the ethical and political dimension of education.

Keywords: Teaching in YAE. Relationships between teachers and students in YAE. The right to Youth and Adult Education.

\section{REFLEXIONES EN TORNO A LAS RELACIONES ENTRE DOCENTES Y EDUCANDOS/AS DE LA EPJA: CAMINOS QUE SE ENCUENTRAN EN LA BÚSQUEDA DE LA GARANTÍA DE UN DERECHO}

\section{RESUMEN}

Este artículo se propone reflexionar sobre las relaciones que se construyen entre docentes y educandos/as de la Educación de Personas Jóvenes y Adultas (EPJA) en escuelas de la Red Municipal de Educación de Belo Horizonte (RME-BH). Los análisis planteados parten de una investigación realizada con docentes que poseen amplias trayectorias de trabajo en la modalidad, las cuales varían 
entre 11 y 32 años de experiencia en el campo. Con el objetivo de describir y analizar dichas relaciones, el artículo indaga sobre cómo los/as docentes participantes de la investigación reconocen las especificidades de los sujetos que asisten a la EPJA en la RME-BH y construyen, junto a ellos/as y el resto de la comunidad, un conjunto de prácticas cuya finalidad es la búsqueda de la garantía del derecho a la educación de todas las personas que llegan a la EPJA, destacando la dimensión ética y política del quehacer educativo.

Palabras clave: Docencia en la EPJA. Relaciones entre docentes y educandos/as de la EPJA. Derecho a la EPJA.

\section{INTRODUÇÃO}

A antropóloga argentina Rita Segato (2018) afirma que vivemos tempos em que prolifera a pedagogia da crueldade. A autora denomina pedagogia da crueldade a todos os atos e práticas que ensinam, habituam e incentivam os sujeitos a transmutar a vida e a sua vitalidade em coisas. Nas suas palavras, trata-se da pedagogia da "captura de algo que fluía errante e imprevisível, como a vida, para instalar nela a inércia e a esterilidade da coisa, mensurável, vendável, comprável e obsolescente" (SEGATO, 2018, p. 11, tradução nossa). Para a autora, a constante espetacularização e repetição da violência da coisificação da vida produz um efeito de normalização de uma paisagem de crueldade, que promove baixos níveis de empatia nos sujeitos e deteriora as possibilidades de construção do tecido social e comunitário que sustenta a vida humana e as sociedades (SEGATO, 2018). Segundo ela, a pedagogia da crueldade torna-se assim indispensável para a manutenção da fase do capital na qual vivemos, já que precisa de sujeitos desmembrados para a sua existência.

Nos dias atuais, quando atravessamos como humanidade a pandemia de COVID-19, a luta pela vida e pelo reconhecimento da vida enquanto processo coletivo, recíproco e interdependente é fundamental. Pensar e fazer da educação um processo de humanização, como Paulo Freire e o seu legado têm nos impulsionado, assume novos sentidos neste tempo histórico. A pedagogia da crueldade, que insiste em "roubar a nossa 
humanidade" (FREIRE, 2005, p. 98) se desenvolve nas mais variadas dimensões do social, incluindo nas próprias práticas e discursos de nossos representantes políticos, com a desmascarada intenção de exibir a sua capacidade de crueldade e incentivando a dessensibilização perante o sofrimento dos outros (SEGATO, 2018).

Porém, como assinala Freire (2015, p. 41), "a desumanização, mesmo que um fato concreto na história, não é, porém, destino dado, mas resultado de uma ordem injusta que gera a violência dos opressores e esta, o ser menos". Sendo assim, retomamos a pergunta de Segato, ao indagar:

[...] como conceber e projetar contra-pedagogias capazes de resgatar uma sensibilidade $\mathrm{e}$ vincularidade que possam se opor às pressões da época e, mais do que tudo, que permitam visualizar caminhos alternativos?" (SEGATO, 2018, p. 15, tradução nossa).

Estas interrogações e reflexões surgiram a partir da pesquisa de mestrado realizada no Programa de Pós-graduação em Educação: Conhecimento e Inclusão Social na Faculdade de Educação da Universidade Federal de Minas Gerais, sobre a docência na Educação de Pessoas Jovens e Adultas (EPJA) nas escolas da Rede Municipal de Educação de Belo Horizonte (RME-BH). A investigação foi desenvolvida no período compreendido entre 2018-2020 e teve como objetivo registrar as experiências de docência de professores/as que possuem uma ampla trajetória na EPJA em escolas das nove regionais da capital mineira. $\mathrm{O}$ intuito foi compreender e analisar os modos particulares nos quais os/as docentes têm exercido o seu trabalho com pessoas jovens, adultas e idosas ao longo de suas trajetórias profissionais na modalidade.

Partiu-se do pressuposto de que a docência na EPJA assume características próprias que a diferenciam do trabalho com crianças. A docência, tanto como campo intelectual como campo de ações de trabalhadores e profissionais da educação, é interpelada e vê-se na necessidade de se pensar de um modo singular frente ao público jovem, adulto e idoso que frequenta as escolas. Isto poderia dar lugar à construção de sentidos diversos para o trabalho de educar $\mathrm{e}$ 
ensinar, assim como contribuir com a reflexão em torno das experiências de docência no campo em questão.

Segundo Soares e Pedroso (2016) refletir sobre as particularidades de ser professor/a de pessoas jovens, adultas e idosas torna-se fundamental considerando as conquistas realizadas na área. As especificidades desse público têm sido reconhecidas, de forma mais ou menos ampla, em diferentes documentos legais e, com isso, a necessidade de uma formação e atuação adequadas do/a educador/a também vêm sendo incorporada. Neste sentido, o próprio Parecer $n^{\circ}$ 093, do ano de 2002, que regulamenta a EPJA na $\mathrm{RME}-\mathrm{BH}$ estabelece que:

\begin{abstract}
O professor precisa ser incentivado a produzir investigação e análise de sua prática com vistas a ampliar suas concepções, buscando elementos teóricos que sustentem a sua ação pedagógica; superando práticas educativas que reproduzem justificativas para as desigualdades sociais; transformando $\mathrm{O}$ ato educativo em criador de alternativas; assumindo as especificidades da EJA, percebendo-se enquanto um profissional que atua numa modalidade educativa diferenciada. (BELO HORIZONTE, 2002, p. 48).
\end{abstract}

Nos aproximar de docentes que possuem uma maior trajetória na modalidade e indagar sobre as suas experiências poderia ser uma forma de registrar e compreender os modos possíveis de criar e recriar o sentido de ser educador/a da EPJA e analisar em que medida se configuram certas especificidades em torno da docência nesta modalidade.

Além disso, a EPJA nas escolas da RME-BH se caracteriza por uma ampla rotatividade docente (SOARES, 2008), devido à fatores como a própria política educativa, que não contempla o concurso específico para trabalhar na modalidade; as condições de trabalho docente nas escolas com EPJA e a escolha dos/as docentes que "passam" pela modalidade, mas não permanecem. Tendo isto em consideração, definimos que seria pertinente investigar as experiências de docência daqueles/as professores/as que, apesar das variadas limitações, permanecem na EPJA há longo tempo. 
Sendo assim, algumas perguntas que guiaram este estudo foram: que reflexões em torno da docência na EPJA puderam ser construídas pelos/as docentes de ampla trajetória na modalidade? Como eles/as têm significado o seu trabalho com esses educandos/as em particular? Que respostas eles/as têm inventado para os diversos desafios enfrentados diariamente? Suas experiências, o que podem nos ensinar?

Para encontrarmos esses/as docentes, partimos da hipótese de que possivelmente em escolas que são consideradas referências na oferta da EPJA na RME-BH poderia haver docentes de maior tempo de trajetória na modalidade. Assim, nos aproximamos dessas escolas e, efetivamente, identificamos nove professoras ${ }^{3}$, uma de cada regional administrativa de Belo Horizonte, que possuem entre 11 e 32 anos de trabalho na EPJA.

Para registrar as suas experiências optamos por realizar entrevistas narrativas partindo da pergunta geradora: Como e em que momento aparece a EJA em sua vida? Como tem sido, desde então, a experiência de ser professora nesta modalidade?

Segundo Connelly e Clandinin (1995), entende-se por "narrativa" tanto a qualidade que estrutura a experiência que vai ser estudada, como o nome dos procedimentos da pesquisa que vão ser utilizados para o seu estudo. Para eles, "a narrativa é tanto o fenômeno que está sendo investigado quanto o método da pesquisa" (CONNELLY; CLANDININ 1995, p. 1, tradução nossa). Sendo assim, consideramos que por meio das entrevistas teríamos acesso à narrativa construída em torno das experiências de docência vivenciadas pelas professoras participantes. Isto é assim porque, ainda segundo os autores citados, a narrativa é a forma de caracterizar a experiência humana, já que como afirma DeloryMomberger (2009, p. 39, tradução nossa) "quando queremos nos apropriar de nossa vida, a narramos". A narrativa constitui-se, então,

\footnotetext{
3 Para a realização da pesquisa, o gênero dos/as docentes não se constituiu como um critério a ser considerado para a inclusão ou não no grupo de professores/as entrevistados/as. Porém, durante o trabalho de campo, não foi possível identificar nas escolas pesquisadas professores que tivessem uma ampla trajetória de trabalho na modalidade e se identificassem com o gênero masculino. Sendo assim, todas as pessoas que participaram da pesquisa se reconhecem como mulheres.
} 
como uma particular reconstrução da experiência por meio da qual, ao fazer um processo reflexivo, se outorga sentido ao acontecido e vivido.

Durante as entrevistas narrativas procuramos "seguir as narradoras", em lugar de assumir uma postura mais diretiva. DeloryMomberger (2012, p. 528) assinala que nas entrevistas narrativas:

Em se tratando de seguir os atores, o narratário não pode mais anteceder o narrador, só pode correr atrás dele e tentar ficar o mais perto possível dele nas sinuosidades, nas bifurcações, nas rupturas dos seus caminhos e dos seus desvios, sem nunca ultrapassá-lo. Ao se manter até o fim esta posição (de epistemologia e de método), chega-se a esta afirmação paradoxal: a questão do narratário só pode vir depois, seu questionamento só pode ser ulterior.

Desta maneira, registramos as narrativas sobre as experiências de docência de nove professoras da RME-BH com ampla trajetória na EPJA. No presente texto, focalizaremos a nossa reflexão nos achados sobre os modos pelos quais as docentes da pesquisa constroem relações e práticas que se organizam em prol da garantia do direito à educação das pessoas jovens, adultas, idosas que frequentam a modalidade na RME-BH.

Buscaremos desenvolver análises que demonstram que as professoras participantes da pesquisa não só reconhecem as especificidades dos sujeitos que frequentam a EPJA na RME-BH, como também constroem, junto com os/as próprios/as educandos/as e o resto da comunidade escolar, um conjunto de ações cuja finalidade é a busca da garantia do direito à educação das pessoas que chegam na EPJA. Isto aponta para uma forma particular de conceber o processo educativo de e com pessoas jovens, adultas e idosas como uma responsabilidade que circula entre os diferentes membros da comunidade; quer dizer, não é unilateral, e se desenvolve sob posições éticas e políticas de cooperação e centralidade da vida. Isto permite reposicionar o lugar dos/as educandos/as nos seus processos de formação, já que mais do que estudantes que recebem uma educação, se colocam como sujeitos 
que produzem, participam e colaboram nas condições de possibilidade de permanência na EPJA e de garantia de uma educação apropriada.

\section{A DIMENSÃO RELACIONAL DA DOCÊNCIA NA EPJA}

Um traço se destaca logo na escuta-leitura desses narradores: indagam sobre si mesmos, sobre sua profissão no espelho dos educandos, nas interações humanas que se dão na relação docente. Redescobrem a docência como uma relação que não se aprende, nem se entende por si mesma [...] Docentes com longos anos de magistério se perguntando o que é possivel ainda fazer de nossas vidas no diálogo com esses educandos na concretude de seu viver.

Miguel Arroyo (2012, p. 434).

As palavras de Arroyo (2012) permitem pensar como, frente a educandos/as que não são aqueles/as compreendidos pelo discurso pedagógico predominante (como o são, por exemplo, as infâncias urbanas), a docência para e se mira no espelho. Os espelhos, então, não refletem uma imagem conhecida, com um caminho a seguir. Os espelhos devolvem uma pergunta. Pensar os/as educandos/as da EPJA como espelhos, como sugere Arroyo (2012), habilita a indagação para o/a educador/a sobre como, quando, para quê e de que modo é possível, esperável e desejável exercer a docência em relação a esses/as educandos/as em particular. Assim, o espelho interpela, questiona e estabelece uma abertura, um diálogo, cujo fundamento é a vida real dos/as educandos/as, a concretude de seu viver. Cabe perguntar, então, o que as docentes desta pesquisa reinventaram ao se olhar no espelho?

$\mathrm{Na}$ "escuta-leitura" das narrativas foi possível compreender que as professoras que participaram desta pesquisa, com as suas amplas trajetórias, nos permitem refletir em torno de uma particular dimensão da docência que diz respeito ao seu aspecto relacional. Trata-se da dimensão que chamaremos de dimensão relacional da docência na EPJA e das configurações que esta assume no particular 
processo educativo que envolve docentes e pessoas jovens, adultas, idosas em escolas municipais da RME-BH.

Nesse sentido, é importante destacar, primeiramente, que uma das principais lutas do campo da EPJA diz respeito ao reconhecimento das especificidades dos sujeitos que frequentam esta modalidade. Isto é assim porque a compreensão das especificidades dos/as educandos/as da EPJA permite refletir e construir práticas pedagógicas apropriadas para o desenvolvimento de ações educativas para e com estes sujeitos.

Nesse sentido, nos interessa focalizar no aspecto das práticas educativas na EPJA que diz respeito às relações estabelecidas entre docentes e educandos/as. Esta temática tem sido levantada por diversos estudos da área ao se encontrarem com a constatação por parte dos/as sujeitos da EPJA (tanto docentes como educandos/as) de que a construção de uma relação ou vínculo entre eles/as tornase uma dimensão extremamente relevante para o desenvolvimento dos processos educativos (LLOSA et al., 2000, LAFFIN, 2007, SOARES; SILVA; SOARES, 2015).

Segundo Soares, Silva e Soares (2015), a partir do estudo de quatro projetos educativos para pessoas jovens, adultas e idosas, constataram que: "como parte da proposta curricular, o acolhimento e a relação educador-educando figuram como uma prática diferenciada" (op. cit., p. 9, grifo nosso). Laffin (2007) também destaca, a partir de sua pesquisa de doutorado com professores/as da EPJA de Santa Catarina, que "o acolhimento" se configura como uma ação central e a descreve como uma intencionalidade por parte dos/as educadores/as para o provimento de condições para o ato de conhecer das pessoas jovens e adultas que frequentam a escola. $\mathrm{Na}$ mesma linha, outras pesquisas têm chamado a atenção sobre a "afetividade" presente na sala de aula na EPJA e na importância da relação entre professores/as e educandos/as como uma dimensão que promove processos favoráveis de ensino e de aprendizagem (LOUREIRO, 1998; CAMARGO, 2017).

Desde outra perspectiva, também é importante destacar aqueles estudos que apontam sobre a recorrência de relações chamadas de "infantilizadoras" na EPJA (VÓVIO, 2007; PORCARO, 
2011) por reproduzirem práticas e recursos que foram originalmente elaborados para o trabalho com a infância.

Porém, isto não se refere apenas à utilização indiscriminada de materiais ou na réplica de ações e estratégias pedagógicas realizadas com crianças transpostas à EPJA, senão que, como destacou pertinentemente Ribeiro (1999), se relaciona com uma visão assistencialista da educação. Assim, a docência com pessoas jovens, adultas e idosas é entendida como uma ação de caráter "social", baseada em uma concepção da ação educativa como "ajuda" aos mais pobres e como caridade. Nesse sentido, ainda é comum escutar na EPJA a referência aos/às educandos/as como sujeitos "carentes", "medrosos/as", com "baixa autoestima", enfim, como pessoas necessitadas de atenções especiais pela sua condição de pobreza e subalternidade.

Pode se dizer que, desde este olhar, a dimensão das relações que se estabelecem entre docentes e educandos/as da EPJA se associa a uma visão em que a docência com pessoas jovens, adultas e idosas consiste, em grande parte, em suprir, seja conhecimento, seja uma carência afetiva, emocional ou de personalidade dos/as educandos/as.

Como veremos adiante, os relatos das professoras que participaram da pesquisa nos permitem pensar de outra maneira a concepção desta dimensão da docência na EPJA.

\section{RELAÇÕES QUE BUSCAM GARANTIR UM DIREITO: DO RECONHECIMENTO À AÇÃo}

Como foi afirmado previamente, a questão da dimensão relacional da docência na EPJA vem sendo abordada de diversas maneiras no campo como uma busca pela compreensão das particulares relações que se estabelecem entre docentes e educandos/as nos processos educativos e que constituem uma dimensão relevante na hora de pensar as ações para e com este público. Sendo assim, nos interessa contribuir com esta discussão no sentido de qualificar o que entendemos ao nomear esta singular relação a partir do material empírico produzido para a pesquisa. 
Para avançarmos nesta análise, se faz pertinente contextualizar ainda mais o histórico de luta pela educação de pessoas jovens, adultas e idosas da RME-BH. Como se explica no Parecer 092-02, os/as docentes da RME-BH tiveram um protagonismo na construção da política pedagógica para EPJA na cidade. Este processo de elaboração coletivo se caracterizou pelo profundo entendimento dos/as educandos/as da EPJA, pessoas jovens e adultas, como sujeitos sócio-culturais, inseridos em diversos tempos e espaços que envolvem não só a escola, como também, e principalmente, o trabalho, a família, a religiosidade, a política, a afetividade.

O parecer expressa a relevância do legado da Educação Popular para a construção da EPJA como modalidade na RME-BH; realça a relação entre o fazer pedagógico e o fazer político, colocando em destaque a dimensão política da ação educativa e do trabalho de educar e ensinar, e destaca o direito dos educandos/as de participarem da construção da proposta pedagógica da EPJA.

A maior parte das professoras entrevistadas relembraram nas suas narrativas os chamados "tempos de efervescência política e pedagógica da prefeitura", que aconteceram durante a década de 1990, quando houve a expansão da RME-BH e a criação e implementação do programa Escola Plural ${ }^{4}$ em 1995. A reflexão coletiva sobre as especificidades do campo da EPJA como modalidade de educação e a sua inserção no programa Escola Plural levou o movimento de educadores/as, professores/as universitários/as, entre outros segmentos da sociedade civil, a definir três pontos fundamentais a serem discutidos e aprofundados para pensar uma política para a EPJA na RME-BH: "o perfil sociocultural dos educandos jovens e adultos, a configuração das dimensões formadoras da vida adulta e a adequação da organização do trabalho,

4 O programa Escola Plural se caracterizou pela reorganização dos tempos e espaços escolares partindo das experiências já existentes nas escolas municipais de Belo Horizonte e visando a promoção da autonomia das instituições para a criação de suas próprias propostas político-pedagógicas. A sensibilidade com a formação humana, a escola como tempo de vivência cultural e experiência de produção coletiva, a busca pela garantia de permanência dos/as alunos/as na escola, a socialização adequada para cada idade/ciclo de formação, a construção de uma nova identidade de escola e seus profissionais, foram alguns dos princípios que regeram o programa. Ver: ROCHA, 2009. 
dos tempos e dos espaços às especificidades da vida adulta" (BELO HORIZONTE, 2000, p. 5).

Fernanda, uma das professoras entrevistadas, relembra na sua entrevista esse passado recente. Quando perguntada sobre como ela observou esse processo sendo recebido pelos/as educandos/as na época, Fernanda dedicou um tempo para pensar e responder. Ela afirma que o aspecto denominado como "acolhimento, acolhida" aos/às educandos/as da EPJA é uma das maiores contribuições que todo o processo de mobilização na EPJA deixou como legado à modalidade; como modo de pensar, formular e fazer a EPJA nas escolas da RME-BH. Ela descreve:

É esse cuidado com o aluno de ouvir, o acolhimento, eu acho que ele se sente muito acolhido e isso é uma, acho que mesmo que a gente não formule isso e a gente nem pensa nisso assim, no dia a dia. Pensa de certa maneira, mas a gente vai fazendo e pensando, sempre pra acolher da melhor maneira possível, de ouvir, de dar atenção e respeito, né, com ele. De entender que foi uma pessoa que foi excluída por várias razões e que acredita ainda que é possível realizar um sonho. [...] Eu acho que essa acolhida, muito mais que qualquer outra coisa. (FERNANDA, 2019).

Quando ela se refere ao termo "acolher", ela explica que, mesmo que seja algo "não formulado", faz parte do dia a dia do trabalho na EPJA. Logo depois, ela menciona o ocorrido no ano anterior com as turmas de EJA externa ${ }^{5}$ que faziam parte da escola. Estas funcionavam em um espaço de uma comunidade próxima que era cedido por um deputado estadual. Ao perder as eleições, de um dia para outro, o ex-deputado decidiu interromper a concessão do local. Assim, a direção da escola iniciou uma mobilização para

\footnotetext{
5 As chamadas "turmas de EJA externa" são um modo de oferta da modalidade na RME$\mathrm{BH}$ que tem como objetivo possibilitar o acesso à educação a pessoas em cujas comunidades não existem escolas municipais que oferecem EPJA, ou que, por diferentes motivos, não se encontram em condições de frequentar uma escola e a oferta de educação deve ser desenvolvida em outro espaço. As turmas externas funcionam em variados espaços da cidade, incluindo hospitais, locais de trabalho, centros culturais das comunidades, igrejas, entre outros.
} 
preservar as três turmas externas. Após meses de negociação, e tendo passado pelo aluguel de uma garagem de vizinhos do bairro para garantir as aulas de EPJA, as três turmas foram abertas na própria escola em horários pouco usuais no que diz respeito à modalidade, sendo uma de manhã e duas de tarde. Fernanda relata que, em comparação a como estavam dadas as condições para o trabalho em turmas externas, especialmente após ter perdido o primeiro espaço, abrir essas turmas na escola foi um ganho. É interessante observar os movimentos que foram iniciados pela instituição para garantir a permanência dos/as educandos na EPJA.

A situação relatada por Fernanda nos permite pensar nessa busca de estratégias que acolhem e têm o nítido objetivo de garantir um direito. Inclusive, ela continua elaborando a sua resposta e relata o seguinte:

A diretora (G) ontem acompanhou aquela minha aluna (M), aquela da carta, você lembra, né? Então aí a $G$, ela escreveu a carta pra mais pessoas, entregou na escola, e o pessoal fez um movimento lá e conseguiu a cesta de alimentos pra ela. E a G foi levar a $\mathrm{M}$ no hospital, porque ela anda a pé. A G falou que é muito longe, muito longe o caminho que ela faz, ficou impressionada. Ela gasta mais de hora, acho que uma hora e quarenta a pé, pra ir e vir. E com problemas no joelho, né... (FERNANDA, 2019).

Fernanda, assim, continuou contando outro tipo de situações em que ela compreende que se está falando sobre "acolhimento". Lia também narra situações similares:

A gente, por exemplo, aqui nós, nós mesmas nos unimos aqui e fazemos cestas básicas pra levar pra essas famílias que precisam, que muitas vezes estão numa situação muito difícil. Acredito que na maioria das escolas os professores sabem assim, os alunos que estão passando... existe um dinheiro de bolsa família que eles recebem, mas muitas vezes a situação é muito pior. Então a gente vai, faz a vaquinha, né. Junta todo mundo e compra os 
alimentos, leva. A gente visita algumas casas. (LIA, 2019).

Como nomear o que a diretora fez ao levar a aluna para o hospital? E a organização das/os professoras/es para buscar garantir a alimentação de determinados estudantes? Se lêssemos essas situações de forma isolada, poderíamos fazer diversas elaborações. Por exemplo, dizer que as professoras estão fazendo algo que não corresponde à ordem do "ensino", do "pedagógico", senão do campo do "assistencial", da "contenção social". Porém, cabe aproximar-nos das realidades narradas em busca de compreender como este tipo de mobilizações faz parte de um conjunto de modos de estar e fazer EPJA, cujos sentidos, intenções e motivações devem ser mais aprofundadas.

Prosseguindo com a análise, Conceição, na sua narrativa, explica porque, segundo ela, a EPJA na escola onde ela trabalha "funciona". Esta escola tem recebido educandos/as de escolas vizinhas que fecharam as turmas de EPJA por diferentes motivos no decorrer do ano 2019.

Mas têm comunidades que são dificílimas, né, têm realidades na EJA que é complicado. Tem um monte de fator que entra aí, né. A questão também da direção. A nossa direção está presente todas as noites na escola. Diretora e vice-diretora. Se uma não está, a outra está. Não tem uma noite que a gente não tem uma das diretoras aqui. Isso tudo faz diferença numa escola, tá? Isso faz diferença na escola. Eu falei isso essa semana, eu falei: Por que aqui funciona a EJA? Porque a gente tem uma direção que quer a EJA na escola, ela quer a EJA na escola, tá? (CONCEIÇÃO, 2019).

"Querer a EJA na escola" pode assumir diferentes significados. Conceição continua explicando como se materializa esse querer.

Eles (os/as educandos/as) têm muitas dificuldades, coisas que a gente assim, não imagina. [...] e eles saem por " $n$ " motivos, " $n$ ". Por incrivel que pareça, ele sai por não ter dinheiro pra pagar um ônibus pra vim pra escola. $\mathrm{O}$ ano passado nós fizemos aqui, nós 
aqui da escola, nós fizemos um mapa com uma trajetória, um trajeto que um ônibus podia fazer aqui no bairro pegando aluno de EJA e deixando em pontos estratégicos para atender em todas as escolas da região. Nós não conseguimos. Porque tem um ônibus aí de manhã, de tarde, pra meninada, mas nós não conseguimos. (CONCEIÇÃO, 2019).

$O$ relato de Conceição permite pensar sobre como a EPJA "funciona" na escola ou, melhor dizendo, como ela se organiza para funcionar e, mais especificamente, como a direção, a coordenação e as/os professoras/es se organizam para fazer a EPJA funcionar. Neste caso, "funcionar" implica se organizar para garantir a permanência dos/as educandos/as da EPJA na escola, implica atender as mais variadas demandas que se apresentam, que são específicas deste público, e implica compreender e defender estas especificidades. Implica, por fim, "acolher"; acolher como se organizar para a garantia do direito à educação de pessoas jovens, adultas e idosas nas escolas.

Ainda buscando qualificar esta organização do acolhimento, que se refere às particulares relações estabelecidas entre docentes e educandos/as, os relatos de Conceição, Fernanda e Lia nos permitem observar que certas práticas circulam dentro da comunidade escolar. Em primeiro lugar, porque ao relatar sobre o "funcionamento" da escola e os movimentos em busca da garantia do direito à educação, seja provendo cesta básica, levando uma estudante no hospital, abrindo turmas em horários incomuns, organizando a luta pela garantia do transporte escolar para o público da EJA, enfim, atendendo às especificidades destes sujeitos, percebe-se que se trata de ações feitas pelo conjunto da comunidade educativa da EPJA. Nesse sentido, Conceição acrescenta:

Isso te ajuda, isso fortalece o trabalho, não faz você ser melhor, faz o grupo ser melhor, não é sua aula que vai ficar melhor, é a escola que vai ficar melhor. [...] Então você tem um retorno, mas não é porque você tem uma aula boa, é porque você tem uma escola boa, um coletivo bom, né. É um coletivo que você vai estendendo, né, chega no aluno, chega até no funcionário, que você pede: "você faz um bolo 
pra minha sala amanhã?" A funcionária faz o melhor bolo, porque ela é acolhida porque os jovens vão trazer um refrigerante e eles vão levar um refrigerante lá pra ela e agradecer pelo bolo. Isso torna o ambiente todo melhor, né. (CONCEIÇÃO, 2019, grifo nosso).

Assim como relata Conceição, essa disposição à mobilização promove uma espécie de círculo virtuoso em que uma ação incentiva e se beneficia de outra, permitindo que este acionar seja mais do que uma iniciativa isolada de um/a docente, caracterizada muitas vezes como uma ação que busca suprir algo que falta (afeto, atenção, saber), e passe a formar parte de uma organização de práticas que adotam outros sentidos, e que também sustentam a construção de uma determinada relação.

Sofia, outra das docentes entrevistadas, nos permite observar isto por meio de uma determinada situação que estava sendo vivida na escola na época da pesquisa. A EPJA estava com possibilidades de fechamento de turmas por não ter alcançado o número suficiente de matrículas. O trecho citado é interessante para observar as mobilizações empreendidas pela equipe frente à situação de ameaça ao direito à educação do público em questão. Ela conta:

Bom, te situando a respeito das negociações, os últimos encontros com a Secretaria de Educação, nós conseguimos um outro prazo. Ainda não sinalizaram que está OK, que podemos seguir aí com os trabalhos tranquilos, não. Há uma pressão de fechamento das turmas, sim, continua, mas deram mais um prazo pra gente matricular mais estudantes. Agora a direção deve comparecer lá de novo, então os coordenadores estão montando um projeto para mostrar o perfil dos alunos, igual a gente fez com as turmas de alfabetização. Com essas turmas nós montamos o perfil e explicamos porque não dá pra trabalhar com alfabetização cheia. E também estamos pedindo para considerar os alunos flutuantes, né, porque os alunos com cinco faltas ou dez alternadas eles (a Secretaria) não estão considerando [...] (SOFIA, 2019). 
Sofia destaca o trabalho feito pela direção, coordenação e professoras/es para tentar garantir todas as turmas abertas. Cuidar, defender e garantir esse direito se apresenta como uma ação que parte do reconhecimento da equipe das especificidades da EPJA e seus sujeitos.

Assim, à medida que nos aproximávamos das interpretaç̃es apresentadas até o momento, foi possível entender que as professoras relatam que este tipo de práticas que acolhem, circulam e viabilizam o trabalho na modalidade, fazem parte da dimensão relacional da docência na EPJA. Como mencionado anteriormente, a relação entre docentes e educandos/as tem sido considerada de grande relevância para a viabilidade das ações educativas propostas para o público da EPJA. A nossa interpretação é que as relações se materializam em um determinado contexto que habilita a construção de práticas, sentidos e processos que promovem formas de se relacionar com os/as educandos/as cujo objetivo é a garantia do direito à educação das pessoas que frequentam a EPJA. A partir do material empírico produzido para a pesquisa, foi possível compreender que nessas relações ambas partes são ativas, tanto docentes como educandos/as. Sendo assim, estas relações não acontecem de forma dada, senão que se constroem com uma intencionalidade que é ética e política.

Nesse sentido, vale retomar as palavras de Freire (2015) ao falar sobre a profissão docente como uma prática que exige um alto nível de responsabilidade ética, da qual a capacidade científica faz parte, mas que também inclui "a razão ética da abertura" (FREIRE, 2015, 133). Para o autor, ensinar exige uma disponibilidade a tocar e ser tocado, como um movimento que é tanto formador como transformador. Nas suas palavras:

Preciso, agora, saber ou abrir-me à realidade desses alunos com quem partilho a minha atividade pedagógica. Preciso tornar-me, se não absolutamente íntimo de sua forma de estar sendo, no mínimo, menos estranho e distante dela. E a diminuição da minha estranheza ou de minha distância da realidade hostil em que vivem meus alunos não é uma questão de pura geografia. Minha 
abertura à realidade negadora de seu projeto de gente é uma questão de real adesão de minha parte a eles e a elas, a seu direito de ser [...] O fundamental é a minha decisão ético-política, minha vontade nada piegas de intervir no mundo (FREIRE, 2015, p. 134)

Lia narra esta relação em termos de "ponte". Na escola onde ela trabalha, algumas circunstâncias se apresentam com maior destaque e urgência, devido à chegada de muitos/as adolescentes na EPJA que tem desafiado ainda mais a organização da escola. Segundo ela, se uma "ponte" não for criada entre professoras/es e estes educandos/as, é muito provável que, nas palavras dela, "você vai afundar mais o abismo que ele (o/a adolescente) já está". Ela continua: "então na hora que ele entra aqui, eu quero ver assim, eu preciso também, construir essa base, sabe? Essa relação com ele. Porque isso é importante pra poder as coisas caminharem".

Em outro sentido, para Mercedes, uma das professoras entrevistadas, estes momentos de fortalecimento das relações se desenvolvem também em atividades realizadas fora da escola. Ela relata:

E essas (saídas), esse projeto de convivência com os alunos, de ampliar, de ocupar outros espaços com eles, isso faz parte do currículo da EJA. [...] E depois eu fui entendendo que nesses lugares você aprimora os vínculos, aproxima mais. Melhora muito, é, a coisa é aproximar, relacionar melhor e aí o trabalho na sala de aula fica mais fácil. Mas nesses momentos também você conversa outras coisas e eles contam coisas [...] E aí você vai, você vai pensar as aulas muito a partir do que você vai conhecendo desses sujeitos, né. $E$ eu faço isso cada vez mais. (MERCEDES, 2019).

Retomando às considerações de Segato (2018), citada no início deste texto, a construção de realidades que permitam ir contra a pedagogia da individualização torna-se fundamental. Assim, uma docência capaz da abertura e da disponibilidade ao outro pode ser um caminho que "inaugura com seu gesto uma relação dialógica" 
(FREIRE, 2015, p. 133), como um movimento que se resiste à crueldade, à fragmentação do tecido social do qual todos/as somos parte.

\section{O ENVOLVIMENTO ENTRE ESCOLA E COMUNIDADE: DO ACOLHIMENTO À COOPERAÇÃO}

Junto com as tentativas para conciliar os diversos tempos, desejos e objetivos que convivem em uma mesma sala de EPJA, entre os/as educandos/as também se desenvolvem relações e circulam práticas que visam garantir um direito. Vejamos como as professoras se referem à esta compreensão:

São gerações muito diferentes, muito diferentes (em uma mesma sala). Mas eu trabalho muito nessa questão assim da cooperação, sabe? Eu acho que tem que ser uma simbiose ali, um ajudando o outro. E vou falando isso muito com eles e eu brinco muito com eles assim: "a gente só vai conseguir superar o ano letivo e chegar no final do ano com uma sala cheia, lotada se um ajudar o outro e se a gente fizer dessa sala de aula uma família. [...] Então eu não tenho essas duas gerações dentro de sala como um conflito não, sabe? Eu, eu tento fazer disso o desafio. E a gente, porque eles trocam muito, e isso é muito bom, sabe? Porque um dá suporte pro outro ali o tempo inteiro. Então é o adulto que chama a atenção do jovem, é o jovem que numa aula de Informática que vira e fala assim: "Oh, senta aqui comigo, você não está sabendo mexer, eu te ensino, eu te ajudo". Então essa troca, eles vão fazendo essa amizade, fazendo esses laços e isso sustenta a sala. (CONCEIÇÃO, 2019).

Mercedes narra como essas relações se constroem também em sua turma:

Agora uma coisa que eu fui aprendendo também no processo é essa coisa de convencer os mais velhos que eles têm que aprender a conviver e convencer 
os mais novos de que eles têm que respeitar os mais velhos. [...] a gente tinha uma aluna aqui muito emburrada, muito séria, conversava muito pouco. E nós recebemos na minha sala um aluno que estava com tornozeleira eletrônica. E... ele cumpriu uma parte da pena e estava cumprindo a outra agora no semiaberto. Esse rapaz de 26 anos fez a G (a aluna) se abrir na sala, por que? Porque ela morria de vergonha de ter filho preso. Quando o M (o aluno) foi acolhido na sala, eu conversei da importância de todos os adultos terem mais paciência. Ele é mais ativo, ele é, ele deve ser, ele não fica muito quieto. $E$ eu falei da importância, da energia que tem o jovem de 26 anos perto das, dos mais velhos, né. A $G$ virou outra pessoa! Ela falta menos hoje e ela contou abertamente que ela tem filho preso. E antes, ela deixou de ter vergonha de ter um filho preso. Ela passou a entender. (MERCEDES, 2019).

A expressão utilizada por Conceição ao dizer de um coletivo que: "vai se estendendo e chega no aluno, até no funcionário", reflete a circularidade das ações que vêm sendo descritas. Estas formam um círculo em que as práticas que acolhem se retroalimentam; ou seja, não se trata apenas de uma via de mão única na qual algo é dado, doado ou cedido a um outro que lhe falta algo e, por isso, deve ser compensado (com educação, conhecimento, escolarização, afeto), senão que todas as partes envolvidas se organizam para contribuir e cooperar em conjunto, construindo relações que promovem a permanência dos sujeitos na EPJA.

Vale recuperar os relatos das professoras sobre a relação estabelecida entre elas e a comunidade de educandos/as que frequenta a escola, ou que já teve algum contato com elas, como equipe, ao longo da sua vida. Por "comunidade" elas também estão se referindo tanto a esse grupo de educandos/as, quanto ao território no qual a escola encontra-se inserida. A maior parte das professoras salienta que uma relação consolidada com as comunidades se configura como mais uma parte desta dimensão relacional da docência na EPJA que promove uma engrenagem de práticas que reconhecem e defendem o direito à educação do público que chega na escola de EPJA. Essa relação da equipe docente com a comunidade 
parece adquirir um lugar relevante no que diz respeito ao suporte do trabalho na EPJA no período noturno, principalmente em territórios que podem ser de potencial conflito. As narrativas das professoras apontam que existe, por um lado, uma certa mediação da própria comunidade para a prevenção de potenciais conflitos dentro da escola. Por outro, elas destacam essa relação como a possibilidade de construção de novas bases ao longo do tempo. Algumas das professoras a descrevem assim:

É uma escola muito bem quista, uma escola que é muito referência pras pessoas aqui do bairro. A gente tem aqui crianças menores, né, de seis até agora no máximo dez anos, à noite tem os adultos, muitos deles são pais, são tios, são avós, também tem uma história com a própria escola, né. Então tem um vínculo e um envolvimento e um abraço, assim, da comunidade do bairro com a escola. [...] eu considero que é uma escola que tem uma relação boa assim, da comunidade ter consciência de preservar essa escola e de cuidar. E os profissionais são muito cuidadosos também assim, com o ambiente da escola, todos os gestores que passaram por aqui sempre se preocuparam por deixar a escola melhor do que já estava, né, até a própria aparência. [...] A vantagem, né, do professor ficar por um tempo na comunidade é mesmo essa construção e essa identidade que a gente tem, já se torna uma referência. (VERÔNICA, 2019).

Sobre o vínculo, o envolvimento e o abraço entre comunidade e escola, Lia afirma:

Mas eu posso andar aqui, a comunidade e a escola têm um laço muito grande, sabe? A comunidade abraça a escola. Se eles verem, eles não aceitam aqui, por exemplo, há casos que se aluno vem de fora, que a comunidade aqui escolar vê que o aluno não é do bairro e que falou de uma forma agressiva comigo, que eles podem até discutir, eles já não vão gostar. Nosso papel é tratar da união ali... Eles têm orgulho da gente estar aqui, sabe? E falam assim, por exemplo, às vezes se eu estiver sem carro e eu 
tiver que subir, eles me acompanham até determinado local, sabe? Se alguma coisa estiver, se eles acharem que eu vou passar por qualquer problema eles chegam e me falam. (LIA, 2019).

Patrícia, outra professora entrevistada, expressa que é a partir da organização e mobilização dessas práticas que se estabelece entre professores/as e educandos/as da EPJA um "vínculo efetivo" que contribui para a permanência dos/as educandos/as na escola, apesar das adversidades que são enfrentadas. A partir do relato dela, porém, foi possível analisar que a EPJA na sua escola tem encarado diversas realidades que vêm debilitando a possibilidade de criar e fortalecer essa relação entre equipe docente e comunidade. Assim, isto que vinha acontecendo em um tempo anterior não tem conseguido se manter. Patrícia explica como funcionava alguns anos atrás a organização destas práticas e a promoção destas relações:

Antes a gente tinha um outro processo inclusive de ir nas vilas para fazer visita, entendeu? A gente ia, às vezes a gente conversava, se o aluno tinha alguma questão, a gente entrava e conversava. A gente ultimamente, aquela história, a gente não está se sentindo segura pra ir, o grupo está pequeno, então... Até isso muda. A gente tinha uma inserção maior na comunidade que hoje não temos. A gente não sabe direito, deve ter no mínimo cinco anos que eu não vou na casa de ninguém assim. Porque você tinha isso mesmo, né, com eles, de sair. Às vezes a gente saia, até, olha que coisa bacana, a gente sabia que o aluno estava fora da escola e a gente ia. E às vezes a gente ia com o próprio colega, com o próprio vizinho que estava aqui estudando. Então tinha um vizinho: "ah, ele não está estudando", a gente ia em busca desse aluno e a gente fazia esse movimento também de trazer o aluno pra escola. Então isso era bacana, se mantinha essa ligação, né, com eles. E acho que a gente ultimamente não tem conseguido isso. (PATRÍCIA, 2019).

Patrícia assinala que a escola onde ela trabalha vem sofrendo mudanças problemáticas para a organização da EPJA. Isto não poderá 
ser abordado com profundidade no presente texto, porém, cabe salientar que se trata de um processo progressivo de redução de turmas que provoca a diminuição da equipe docente disponível para a EPJA, junto com uma menor capacidade para o desenvolvimento de propostas pedagógicas apropriadas. Apesar disso, é relevante destacar que todas as professoras entrevistadas salientam o papel ativo da comunidade como um todo, quer dizer, entendida como o grupo de educandos/as, ex-educandos/as e famílias, para a viabilização da EPJA nas escolas.

Como elas destacam, o reconhecimento, cuidado e preservação dessa relação entre a escola e a comunidade acontece de forma singular na EPJA, em correspondência com o público atendido. Estas relações se desenvolvem porque existe um contexto, uma história, uma forma de organização que as habilita, em um processo no qual todos/as os/as envolvidos/as têm um papel relevante. Nesse sentido, cabe reforçar a importância de a equipe docente das escolas terem uma ampla trajetória de trabalho na modalidade e nas próprias escolas nas quais atuam. Este fato da permanência nas escolas, não só dos sujeitos educandos/as, mas principalmente dos/as educadores/as da EPJA, se constitui como um fator primordial para a construção das relações que incentivam o envolvimento de todos os sujeitos com o direito à educação.

\section{OS SUJEITOS NO CENTRO, A VIDA NO CENTRO}

Quais são os sentidos que guiam as relações analisadas no presente texto? Podemos afirmar que as mesmas se fundam na conviç̧ão de que o direito à educação supera a busca pela transmissão de conhecimentos, e implica, portanto, o entendimento de que a EPJA se constitui como um espaço-tempo em que as próprias vidas dos sujeitos envolvidos se (re)constroem, sustentam e formam mutuamente. Assim, "a atividade docente de a que a discente não se separa" (FREIRE, 2015, p. 139) assume formas particulares. Nas palavras do autor:

É digna de nota a capacidade que tem a experiência pedagógica para despertar, estimular e desenvolver 
em nós o gosto de querer bem e o gosto da alegria, sem a qual a prática educativa perde o sentido [...]. Mas é preciso, sublinho, que, permanecendo e amorosamente cumprindo o seu dever, (o docente) não deixe de lutar politicamente por seus direitos e pelo respeito à dignidade de sua tarefa, assim como pelo zelo devido ao espaço pedagógico em que atua com seus alunos (FREIRE, 2015, p. 139).

Partindo destas reflexões, a análise proposta neste texto busca oferecer outras referências para a interpretação e expressão deste encontro entre docentes e educandos/as da EPJA, o qual produz relações que se sustentam não só na reciprocidade, mas também na apropriação e (re)construção da dimensão política da docência, "como qualidade que tem a prática educativa de não poder ser neutra" (FREIRE, 2015, p. 68).

Dussel e Southwell (2005) propõem uma posição políticopedagógica para a docência e as escolas em que assumir a responsabilidade signifique serem responsáveis com os/as outros/as de um mundo em comum, já que: "o lugar do outro é um espaço e um tempo que se produz no tecido que uns fazem para buscar ao outro. O lugar do outro é um assunto que se constrói entre palavras, gestos, miradas e histórias que se colocam em comum". (Op. Cit., 2005, p. 31, tradução nossa). Mais uma vez, como vem se afirmando, a construção das relações entre docentes, educandos/as, enfim, a comunidade educativa como um todo, não se trata de um acontecimento unilateral. A dimensão relacional da docência na EPJA envolve o reconhecimento das pessoas que a frequentam como sujeitos de direitos que se mobilizam para garanti-los, que se envolvem e se responsabilizam na defesa da sua dignidade e desenvolvimento de suas vidas (ARROYO, 2017), pela sua humanização (FREIRE, 2015).

Sendo assim, as relações aqui analisadas se enraízam também em uma ética que coloca a sustentabilidade da vida no centro (OROZCO, 2013). Em oposição aos valores impostos e reproduzidos pela ética do mercado e do capitalismo nas diferentes esferas sociais que vivemos, colocar a sustentabilidade da vida no centro significa reconhecer que a vida é possível, mas que não acontece sempre e em 
qualquer circunstância. Seguindo a autora citada, organizar as nossas práticas sociais em torno desta noção implica um posicionamento ético que reconhece que uma vida possível se torna uma vida efetiva apenas na vida em comum com outras vidas, na interdependência.

Tendo isto em consideração, podemos afirmar que as práticas realizadas e sustentadas nas diversas relações estabelecidas entre docentes, educandos/as, e outros membros da comunidade educativa da EPJA se fundamentam, também, em uma ética que, ao colocar o sujeito no centro, deve colocar a vida e as condições de sua possibilidade em primeiro lugar. Isto se baseia em uma compreensão da educação como um direito humano que é muito mais do que um percurso escolar exitoso, já que este se configura como um articulador entre a pluralidade de direitos humanos ainda não garantidos (ARROYO, 2017). Assim, a EPJA como experiência de afirmação de direitos (ARROYO, 2017), pode se organizar em torno de relações, práticas, sentidos e posições que além do certificado de conclusão de um nível educativo, tem promovido a sustentabilidade da vida. Isto não se faz de forma individual e isolada, senão coletiva, circular e interdependente.

\section{CONSIDERAÇÕES FINAIS}

Voltando às reflexões de Segato (2018), a autora afirma que existem hoje dois projetos históricos em disputa: o projeto histórico do capital ou "das coisas" e o projeto histórico dos vínculos. Segundo ela, o projeto histórico do capital, promovido pela pedagogia da crueldade, impulsiona uma relação vazia entre as pessoas que acaba se transformando em uma relação entre funções, utilidades e interesses. Por sua vez, o projeto histórico dos vínculos, explica a autora, incita ao enraizamento e a construção do tecido social e comunitário que se faz necessário para sustentar qualquer vida.

Considerando estas reflexões, pretendeu-se analisar as relações construídas entre docentes e educandos/as na EPJA. Buscouse destacar que a dimensão relacional da docência nesta modalidade em particular se desenvolve a partir de determinadas posições, éticas e políticas, que reconhecem as especificidades dos/as educandos/as e promovem práticas que visam garantir o direito à educação dos 
mesmos. Sendo assim, os vínculos gerados, tanto entre docentes e educandos/as, como entre os/as próprios/as educandos/as, e entre a equipe docente e a comunidade escolar mais ampla, demonstram a capacidade que tem a EPJA de se mobilizar e se constituir como um espaço-tempo em que é "o mundo não é, o mundo está sendo" (FREIRE, 2015, p. 74). Dessa maneira, se ampliam as possibilidades de criar outros modos de estar no mundo e no próprio fazer educativo menos cruéis e, portanto, mais empáticos e comunitários.

As análises apresentadas também permitiram qualificar o que se costuma compreender como "acolhimento" nas práticas educativas na EPJA, aprofundando nas formas nas quais se desenvolvem essas práticas e na definição de suas motivações. Além disso, o trabalho de interpretação e reflexão sobre os dados produzidos para a pesquisa, demonstraram que 0 fato de as professoras entrevistadas terem uma longa trajetória de trabalho na EPJA assumiu uma centralidade na hora de compreender a dimensão relacional da docência nesta modalidade. As docentes, ao permanecerem na EPJA por longos anos e, em geral, em uma mesma escola, foram capazes de construir não só conhecimentos e práticas apropriadas para o desenvolvimento de seus trabalhos, mas também sólidas relações com a comunidade de educandos/as que faz e/ou fez parte da escola, a qual, ao mesmo tempo, se insere em determinados territórios. Isto possibilitou confirmar a relevância da permanência dos/as professores/as na EPJA, em contraposição à recorrente rotatividade docente que caracteriza a área na RME-BH.

É possível afirmar, finalmente, que a intencionalidade das relações e práticas que foram aqui analisadas não partem de uma visão que infantiliza o/a outro/a ou simplesmente o assiste, dandoIhe algo que não possui, senão que se constroem em determinados contextos de colaboração entre os diversos sujeitos da comunidade educativa, que se organizam para juntos/as, defender o direito à educação das pessoas que frequentam a EPJA. 


\section{REFERENCIAS}

ARROYO, Miguel G. Posfácio para Viver e Contar: experiências e práticas de professores de matemática, de Teixeira I. A. de Castro et al. 1 ed., 433-443. São Paulo: Livraria da Física, 2012.

ARROYO, Miguel G. Passageiros da noite: do trabalho para a EJA. Itinerários pelo direito a uma vida justa. Petrópolis: Vozes, 2017.

BELO HORIZONTE. Cadernos da Escola Plural - EJA: a construção de diretrizes político-pedagógicas para a Rede Municipal de Ensino de Belo Horizonte. 2000.

BELO HORIZONTE. Conselho Municipal de Educação. Parecer $\mathbf{n}^{\circ}$ 093/2002, de 07 de novembro de 2002. Regulamentação da Educação de Jovens e Adultos nas Escolas Municipais de Belo Horizonte. 2002.

CAMARGO, Poliana da S. A. S. Representações Sociais de docentes da EJA: afetividade e formação docente. In: Educação \& Realidade. Porto Alegre, v. 42, n. 4, p. 1567-1589, out./dez. 2017. Acesso em out. de 2020. Disponível em: http://dx.doi.org/10.1590/2175623663306 .

CONNELLY, F. M; CLANDINNIN, J. D. Jean. Relatos de experiencia e investigación narrativa. In: LARROSA, J. y otros. Déjame que te cuente. Ensayos sobre narrativa y educación. Barcelona: Laertes. 1995.

DELORY-MOMBERGER, Christine. Biografía y educación: figuras del individuo-proyecto. Buenos Aires: Editorial de la Facultad de Filosofía y Letras Universidad de Buenos Aires; Consejo Latinoamericano de Ciencias Sociales. 2009.

DELORY-MOMBERGER, Christine. Abordagens metodológicas na pesquisa biográfica. In: Revista Brasileira de Educação. v. 17 n. 51 set.-dez. 2012.

DUSSEL, Inés; SOTHWELL, Myriam. Cuidar enseñando. In: El Monitor. Revista del Ministerio de Educación, Ciencia y Tecnología de la Nación. v. 5. n. 4. 2005. 
FREIRE, Paulo. Pedagogia do Oprimido. Rio de Janeiro: Paz e Terra, 2005.

FREIRE, Paulo. Pedagogia da Autonomia: saberes necessários à prática educativa. Rio de Janeiro: Paz e Terra, 2015.

LAFFIN, María H. L. A constituição da docência entre professores de escolarização inicial de jovens e adultos. Tese de Doutorado. Programa de Pós Graduação em Educação. Universidade Federal de Santa Catarina. 2007. 216p.

LLOSA, Sandra et al. La situación de la Educación de Jóvenes y Adultos em la Argentina. CD-ROM- $23^{a}$ Reunião Anual da Anped, Caxambu: MG, 2000.

LOUREIRO, T. C. Afetividade, conteúdo e metodologia: diagnosticando as relações que se constroem em sala de aula na visão do aluno adulto. 1998. Trabalho apresentado à $21^{\text {a }}$ Reunião Anual da ANPEd, Caxambu, 1998.

OROZCO, Amaia P. La sostenibilidad de la vida en el centro, ¿y eso qué significa? 2013. Trabalho apresentado a $4^{a}$ Jornada Economía Feminista. 2013.

PORCARO, Rosa. Caminhos e desafios da formação de educadores de jovens e adultos. Tese de doutorado. Programa de Pós-graduação em Educação. UFMG. Belo Horizonte, 2011. 186 p.

RIBEIRO, Vera M. A formação de educadores e a constituição da educação de jovens e adultos como campo pedagógico. In:

Educação \& Sociedade. Ano XX, . ${ }^{\circ}$ 68, dez. 1999.

ROCHA, Maria da C. Políticas de valorização do magistério: remuneração, plano de carreira, condições de trabalho - uma análise da experiência de Belo Horizonte. Tese de Doutorado. Programa de Pós Graduação em Educação. Universidade de São Paulo. 2009.

SEGATO, Rita. Contra-pedagogías de la crueldad. Ciudad Autónoma de Buenos Aires: Prometeo Libros. 2018. 112p. 
SOARES, Leôncio J. G. O educador de jovens e adultos e sua formação. In: Educação em Revista. Belo Horizonte, n. 47, p. 83100, jun. 2008.

SOARES, Leôncio J. G.; PEDROSO, Ana Paula F. Formação de educadores na educação de jovens e adultos (EJA): Alinhavando contextos e tecendo possibilidades. In: Educação em Revista. Belo Horizonte. v.32. n.04. p. 251-268. Outubro-Dezembro 2016.

SOARES, Leôncio J. G.; SILVA, Fernanda R.; SOARES, Rafaela Carla e $S$. Educação de jovens e adultos e propostas curriculares: (re)conhecer especificidades dos sujeitos. 2015. Trabalho apresentado à $37^{\text {a }}$ Reunião Nacional da ANPEd. UFSC Florianópolis. 2015.

VÓVIO, Cláudia Lemos. Entre discursos: sentidos, práticas e identidades leitoras de alfabetizadores de adultos. Tese de Doutorado. Instituto de Estudos da Linguagem. Universidade Estadual de Campinas. 2007. 287p.

Submetido em: Julho/ 2021.

Aceito em: Setembro/ 2021. 